Note

\title{
Summer movements of a radio-tagged Hoary Bat (Lasiurus cinereus) captured in southwestern Ontario
}

\author{
Derek MorningStar ${ }^{1, *}$ and Al SANDilands ${ }^{2}$ \\ ${ }^{1}$ Myotistar, 51 Silverthorne Drive, Cambridge, Ontario N3C 0B4 Canada \\ ${ }^{2} 1356$ Lockie Road, Branchton, Ontario N0B 1L0 Canada \\ *Corresponding author: myotistar@gmail.com
}

Morningstar, D., and A. Sandilands. 2019. Summer movements of a radio-tagged Hoary Bat (Lasiurus cinereus) captured in southwestern Ontario. Canadian Field-Naturalist 133(2): 125-129. https://doi.org/10.22621/cfn.v133i2.2148

\begin{abstract}
Hoary Bat (Lasiurus cinereus) is a migratory species known to travel long distances during migration. Little is known about its movement patterns during other periods. An adult male Hoary Bat that we radio-tagged in southwestern Ontario in summer was tracked using the Motus Wildlife Tracking System. It travelled a minimum of $827 \mathrm{~km}$ in a circular route over a 2 -week period and was last recorded $46 \mathrm{~km}$ from the original capture site. Hoary Bat is highly vulnerable to being killed at wind turbines and its propensity to travel great distances during summer and migration may exacerbate the impacts of wind farms.
\end{abstract}

Key words: Hoary Bat; Lasiurus cinereus; summer movement; Motus; radio-tracking; southwestern Ontario

Hoary Bat (Lasiurus cinereus) is widely distributed throughout the Western Hemisphere, and may be common in the Great Lakes Region. However, it is among the least frequently encountered species in studies of regional bat communities (e.g., Jung et al. 1999).

Hoary Bat travels long distances through its life cycle (Cryan et al. 2014). Migratory movements of this species have mostly been inferred from the seasonal distribution of museum specimens (Cryan 2003; Cryan et al. 2014), but there are several biases in these data. Kurta (2010) demonstrated that studies based on museum specimens did not match actual distribution and sex ratios of Hoary Bats captured by mist-netting in Michigan. This species is frequently studied through acoustic inventories (e.g., Barclay et al. 1999) and mortality studies at wind power facilities (e.g., Kunz et al. 2007). Such studies provide no information on individual movement patterns, which can only be determined through physical handling and tracking of individuals. Only one study has documented the long-distance movements of Hoary Bats in North America (Weller et al. 2016), and it was conducted in autumn rather than summer.

The non-migratory movements of males have not been well documented. Banfield (1974) stated that males seem to wander erratically during spring and summer and do not associate with females while the latter are caring for their young. Here we provide data on the short-term movements of a radio-tracked male Hoary Bat during mid-summer.

On 9 July 2016, we captured an adult male Hoary Bat in a 12-m triple high mist net near a Little Brown Myotis (Myotis lucifugus) maternal roost near Branchton, Ontario $\left(43.2986^{\circ} \mathrm{N}, 80.2900^{\circ} \mathrm{W}\right)$. The Hoary Bat was $29.2 \mathrm{~g}$ at the time of capture and had a forearm length of $51 \mathrm{~mm}$. A Nanotag radio transmitter (Lotek, Newmarket, Ontario, Canada) was affixed to the back of the bat by shaving a small area and applying a small amount of Osto-Bond (Montreal Ostomy Inc., Vaudreuil-Dorion, Quebec, Canada) glue to the bat and the tag. The mass of the tag reported by the manufacturer was $0.33 \mathrm{~g}$, representing $1.1 \%$ of the body mass of the bat, less than the maximum of $5 \%$ recommended by Aldridge and Brigham (1988). This brand of skin cement is effective for adhesion of the tag to the bat for at least several days (Carter et al. 2009), and the transmitter battery life is expected to be as long as 21 days. Once the glue had dried, the bat was released at the capture site.

We attempted to relocate the bat by driving roads within $5 \mathrm{~km}$ of the capture site for seven days after capture, using two 4-element Yagi antennae fixed in opposite directions to the roof of a truck and connected to an SRX800 receiver (Lotek). The bat was

$\overline{\text { A contribution }}$ towards the cost of this publication has been provided by the Thomas Manning Memorial Fund of the Ottawa Field-Naturalists' Club. 
never detected from the ground; thus, tracking its movements relied on detections on the Motus Wildlife Tracking System.

The Motus system is an international collaborative research network that uses coordinated automated radio telemetry arrays to study movements of small animals (Taylor et al. 2017); it has been used for tracking migratory bats (Lagerveld et al. 2017). Bird Studies Canada maintains an array of more than 100 automated radio telemetry stations in Ontario, and The Ohio State University maintains other stations in Ohio used by this study. Although these do not provide complete coverage of all areas and are not suitable for precise triangulation, detections show large landscape movements. Detection of tags at a receiver station could be within $15 \mathrm{~km}$ of the station depending on station strength and whether the animal is flying in the open or near obstructions (Taylor et al. 2017). The nearest receiver station to the capture site (Onondaga) was $\sim 2 \mathrm{~km}$ south, but it was not activated until 12 July 2016 (seven days after we tagged the bat); the bat was never detected at this station.

Figure 1 depicts the movements of the bat, although it did not necessarily travel in a straight line between stations. The specific locations of the stations where it was detected are provided in Table 1 along with the dates and times when the bat was detected. Over two weeks, the Hoary Bat travelled a minimum distance of $827 \mathrm{~km}$ and was last detected only $46 \mathrm{~km}$ from the banding location. The landscape that it moved through was predominantly agricultural with scattered remnants of forest and wetland.

The male Hoary Bat made significant movements within short periods (Table 1): the longest were a minimum of $253 \mathrm{~km}$ over one night and $316 \mathrm{~km}$ over three nights (although it is unknown how long the

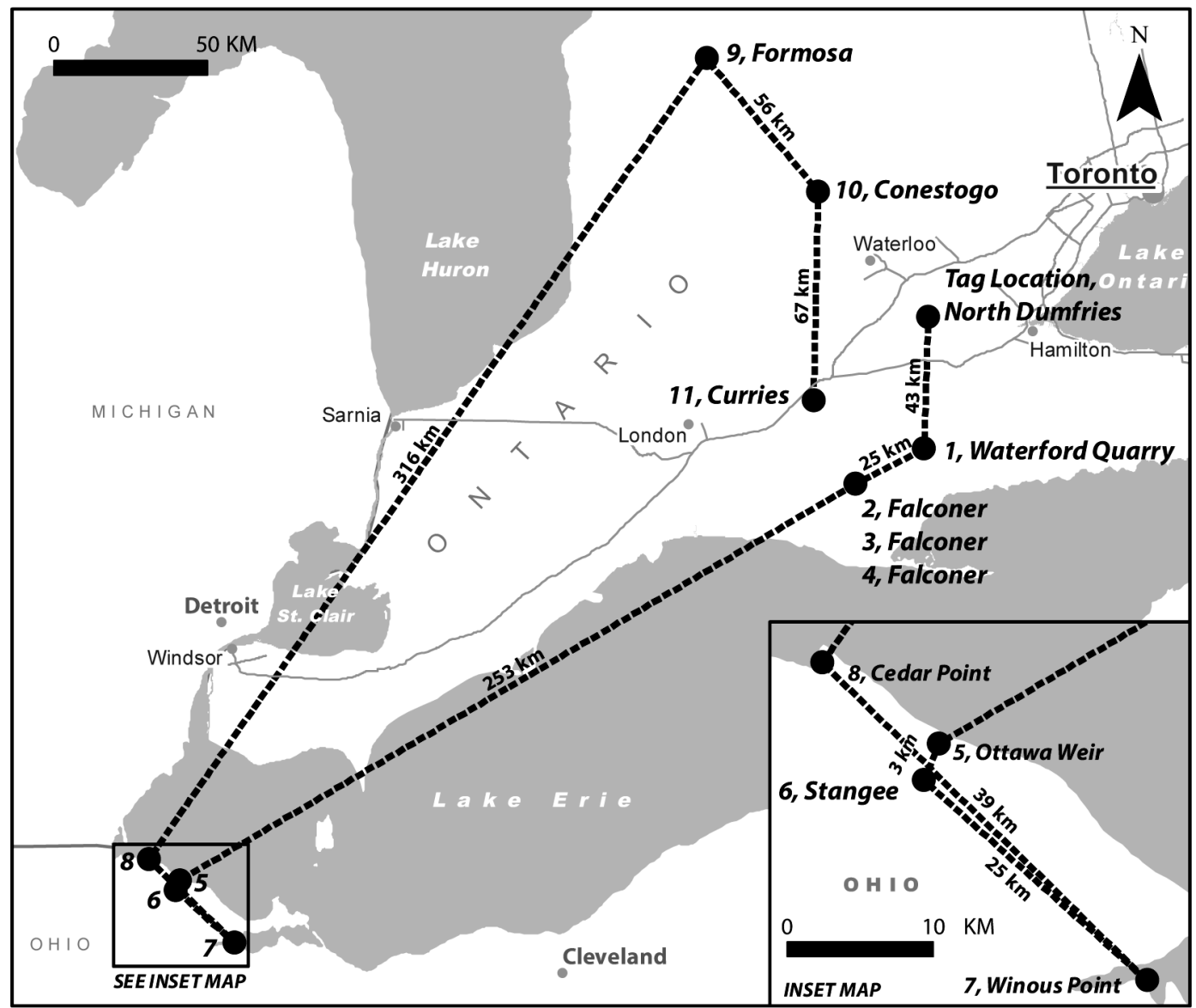

Figure 1. The map indicates the location where the male Hoary Bat (Lasiurus cinereus) was tagged on 9 July 2016 (North Dumfries) and its subsequent detections at the various Motus stations: 1. Waterford Quarry; 2, 3, 4. Falconer; 5. Ottawa Weir; 6. Stangee; 7. Winous Point; 8. Cedar Point; 9. Formosa; 10. Conestogo; 11. Curries. The inset map shows its movements in Ohio on 19 July 2016. 
TABLE 1. Movements of a radio-tagged Hoary Bat (Lasiurus cinereus) over a 2-week period in July 2016 in southwestern Ontario.

\begin{tabular}{llcc}
\hline \hline Motus station* & Date and time detected & $\begin{array}{c}\text { Distance from } \\
\text { last station, km }\end{array}$ & $\begin{array}{c}\text { Cumulative distance } \\
\text { travelled, km }\end{array}$ \\
\hline North Dumfries (tagging location) & 9 July, 2350 & 0 & 0 \\
1. Waterford Quarry & 14 July, 1943-2200 & 43 & 43 \\
2. Falconer & 15 July, 2229-2303 & 25 & 68 \\
3. Falconer & 16 July, 2005 & 0 & 68 \\
4. Falconer & 18 July, 1912-1929 & 0 & 68 \\
5. Ottawa Weir & 19 July, 1728-1730 & 253 & 321 \\
6. Stangee & 19 July, 1732-1743 & 3 & 324 \\
7. Winous Point & 18 July, 1731-1736 & 25 & 349 \\
8. Cedar Point & 19 July, 1743-1744 & 39 & 388 \\
9. Formosa & 22 July, 1954-1955 & 316 & 704 \\
10. Conestogo & 22 July, 2129-2133 & 56 & 760 \\
11. Curries & 23 July, 2229-2349 & 67 & 827 \\
\end{tabular}

*Numbers correspond to those on the map in Figure 1.

bat took to fly these distances). The movements were not in a clear latitudinal direction. The bat initially moved to the southwest along or over Lake Erie, then flew quickly back to the northeast along or over Lake Huron and started another trip toward the southwest. It spent some time north of the Long Point area at Falconer and in the Cedar Point area of Ohio and was last detected at the Curries station (also near Long Point). The bat was detected consistently early in the night and often during daylight hours. If the bat was not moving at this time, we would have expected it to be detected repeatedly at individual stations until it moved out of the detection range. The bat did not appear to return to the location where it was captured during our sample period, because it was never detected at the Onondaga or other nearby stations.

Our study reports the first documented movements of an adult male Hoary Bat during the summer months. It has been widely believed that Hoary Bat makes long-distance movements during migration, but concrete evidence of this is sparse; even less information is available on local summer movements, such as those documented here. The few recoveries of banded Hoary Bats show maximum distances between banding and recovery sites of $150-450 \mathrm{~km}$, representing more local movements (Davis 1969, 1970), although isotope analysis has shown that Hoary Bats make long-distance seasonal movements (Arias 2014; Baerwald et al. 2014).

In autumn in California, Weller et al. (2016) recovered three adult male Hoary Bats with global positioning system tags. One remained sedentary during the study, one made local movements of less than 100 $\mathrm{km}$, and the third travelled over $1000 \mathrm{~km}$ in a month. Similar to the bat that we tracked, it moved in a circular manner and ended up less than $150 \mathrm{~km}$ from the original capture location. Results from this observa- tion and Weller et al. (2016) indicate that male Hoary Bats may occasionally make circular or other longdistance movements lasting several days and covering distances as great as $1000 \mathrm{~km}$. Although sample size is still very small (two of four tracked bats), this indicates that these bats have a large home range and, therefore, habitat protection or conservation for the species must similarly be on a large scale. The purpose of these flights is uncertain: bats may be searching for females to mate with before migration (Weller et al. 2016), although this bat was not scrotal (showing signs of sexual reproduction by having distended testes). More studies that use the Motus system or other methods capable of tracking Hoary Bats are recommended to better understand the space use by this fast, high-flying bat.

Hoary Bats are frequently killed at wind power facilities, particularly during late summer and autumn migration (Arnett et al. 2007; Bird Studies Canada et al. 2016). Hayes et al. (2015) concluded that Hoary Bats make up approximately $40-50 \%$ of all bat mortalities at wind farms; in Canada, this figure is $30.9 \%$ (Bird Studies Canada et al. 2016). Cryan (2011) estimated that as many as 225000 Hoary Bats might be killed annually at North American wind farms, and it is predicted that the Hoary Bat population could decline by $90 \%$ in the next 50 years because of mortality related to wind turbines (Frick et al. 2017). Over the landscape that this bat travelled, a considerable number of wind turbines are in operation. Ontario has the greatest wind power generation in Canada with more than $4781 \mathrm{MWh}$ of annual power production as of 2016 (Canadian Wind Energy Association 2017); many of the turbines are in southwestern Ontario. This bat either avoided those turbines or flew through them without being killed during the period that it was tracked. Our data provide 
evidence that Hoary Bats are at risk of encountering a large number of wind turbines during their summer movements, not just during migration.

\section{Acknowledgements}

This study was funded in part by the Canadian Wildlife Service. We thank Stu Mackenzie for his thoughtful review and insight on an earlier draft. Field assistance was provided by Lucas Greville, Luke Owens, Roberto Valdizon, Alejandra CeballosVasquez, Chris Risley, and Patricia Ronald. We are indebted to Bird Studies Canada and collaborators in the Motus Wildlife Tracking System for the Ontario stations and to Chris Tonra and The Ohio State University for operation of the Ohio stations; without the Motus system, this work would not have been possible. We thank Andy McLennan of Cartographics Mapping \& Design Inc. for preparing the map. Capture and handling of bats was conducted under authorization of Wildlife Animal Care Protocol \#16-335 and Wildlife Scientific Collector's Authorization \#1083372, both issued by the Ontario Ministry of Natural Resources and Forestry. Comments from D.A.W. Lepitzki, T.S. Jung, and two anonymous reviewers improved previous drafts of this manuscript.

\section{Literature Cited}

Aldridge, H.D.J.N., and R.M. Brigham. 1988. Load carrying and maneuverability in an insectivorous bat: a test of the 5\% "rule" of radio-telemetry. Journal of Mammalogy 69: 379-382. https://doi.org/10.2307/1381393

Arias, L. 2014. Using stable isotope analysis to study altitudinal and latitudinal bat migration. Ph.D. thesis, Indiana State University, Terre Haute, Indiana, USA.

Arnett, E.B., D.B. Inkley, D.H. Johnson, R.P. Larkin, S. Manes, A.M. Manville, R. Mason, M. Morrison, M.D. Strickland, and R. Thresher. 2007. Impacts of wind energy facilities on wildlife and wildlife habitat. Technical review 07-2. Wildlife Society, Bethesda, Maryland, USA. Accessed 7 May 2017. https://wildlife. org/wp-content/uploads/2014/05/Wind07-2.pdf.

Baerwald, E.F., W.P. Patterson, and R.M.R. Barclay. 2014. Origins and migratory patterns of bats killed by wind turbines in southern Alberta: evidence from stable isotopes. Ecosphere 5: 1-17. https://doi.org/10.1890/ES 13-00380.1

Banfield, A.W.F. 1974. The Mammals of Canada. National Museums of Canada, Ottawa, Ontario, Canada.

Barclay, R.M.R., J.H. Fullard, and D.S. Jacobs. 1999. Variation in the echolocation calls of the hoary bat ( $\mathrm{La}$ siurus cinereus): influence of body size, habitat structure, and geographic location. Canadian Journal of Zoology 77: 530-534. https://doi.org/10.1139/z99-008

Bird Studies Canada, Canadian Wind Energy Association, Environment Canada, and Ontario Ministry of Natural Resources. 2016. Wind energy bird and bat monitoring database: summary of the findings from post-construction monitoring reports. Port Rowan, Ontario, Canada. Accessed 26 September 2019. https:// docs.wind-watch.org/Bird-Studies-CAN-Jul2016 Wind.pdf.

Carter, T.C., T.J. Sichmeller, and M.G. Hohmann. 2009. A field- and laboratory-based comparison of adhesives for attaching radiotransmitters to small insectivorous bats. Bat Research News 50: 81-85.

Canadian Wind Energy Association. 2017. Wind is Canada's largest source of new electricity generation for more than a decade. Canadian Wind Energy Association, Ottawa, Ontario, Canada. Accessed 3 October 2018. https://canwea.ca/news-release/2017/01/31/windenergy-continues-strong-growth-canada-2016/.

Cryan, P.M. 2003. Seasonal distribution of migratory tree bats (Lasiurus and Lasionycteris) in North America. Journal of Mammalogy 84: 579-593. https://doi.org/10. 1644/1545-1542(2003)084<0579:sdomtb $>2.0$. co;2

Cryan, P.M. 2011. Wind turbines as landscape impediments to the migratory connectivity of bats. Environmental Law Review 41: 355-370. Accessed 6 July 2017. http:// elawreview.org/articles/volume-41/issue-41-2/windturbines-as-landscape-impediments-to-the-migratoryconnectivity-of-bats/?hilite="cryan".

Cryan, P.M., C.A. Stricker, and M.B. Wunder. 2014. Continental-scale, seasonal movements of a heterothermic migratory tree bat. Ecological Applications 24: 602-616. https://doi.org/10.1890/13-0752.1

Davis, W.H. 1969. A recovery of a banded Hoary Bat. Bat Research News 10: 41.

Davis, W.H. 1970. Recovery of a banded Lasiurus cinereus. Bat Research News 11: 30.

Frick, W.F., E.F. Baerwald, J.F. Pollock, R.M.R. Barclay, J.A. Szymanski, T.J. Weller, A.L. Russell, S.C. Loeb, R.A. Medellin, and L.P. McGuire. 2017. Fatalities at wind turbines may threaten population viability of a migratory bat. Biological Conservation 209: 172-177. https://doi.org/10.1016/j.biocon.2017.02.023

Hayes, M.A., P.M. Cryer, and M.B. Wunder. 2015. Seasonally-dynamic presence-only species distribution models for a cryptic migratory bat impacted by wind energy development. PLoS One 10: e0132599. https:// doi.org/10.1371/journal.pone.0132599

Jung, T.S., I.D. Thompson, R.D. Titman, and A.P. Applejohn. 1999. Habitat selection by forest bats in relation to mixed-wood stand types and structure in central Ontario. Journal of Wildlife Management 63: 13061319. https://doi.org/10.2307/3802849

Kunz, T.H., E.B. Arnett, B.M. Cooper, W.P. Erickson, R.P. Larkin, T. Mabee, M.L. Morrison, M.D. Strickland, and J.M. Szewczak. 2007. Assessing impacts of wind-energy development on nocturnally active birds and bats: a guidance document. Journal of Wildlife Management 71: 2449-2486. https://doi.org/10.2193/ 2007-270

Kurta, A. 2010. Reproductive timing, distribution, and sex ratios of tree bats in Lower Michigan. Journal of Mammalogy 91: 586-592. https://doi.org/10.1644/09mamm-a-308.1

Lagerveld, S., R. Janssen, J. Manshanden, A.-J. Haarsma, S. De Vries, R. Brabant, and M. Scholl. 2017. 
Telemetry for migratory bats — a feasibility study. Technical report. Wageningen University, Den Helder, Netherlands. https://doi.org/10.18174/417092

Taylor, P.D., T.L. Crewe, S.A. Mackenzie, D. Lepage, Y. Aubry, Z. Crysler, G. Finney, C.M. Francis, C.G. Guglielmo, D.J. Hamilton, R.L. Holberton, P.H. Loring, G.W. Mitchell, D.R. Norris, J. Paquet, R.A. Roncini, J.R. Smetzer, P.A. Smith, L.J. Welsh, and B.K. Woodworth. 2017. The Motus Wildlife Tracking System: a collaborative research network to enhance the understanding of wildlife movement. Avian Conservation and Ecology 12: 8. https://doi.org/10.5751/ ace-00953-120108

Weller, T.J., K.T. Castle, F. Liechti, C.D. Hein, M.R. Schirmacher, and P.M. Cryer. 2016. First direct evidence of long-distance seasonal movements and hibernation in a migratory bat. Scientific Reports 6: 34585 . https://doi.org/10.1038/srep34585

Received 10 October 2018

Accepted 31 July 2019 